\title{
The Children with Cerebral Palsy: Clinical Features and Causes
}

\author{
Zmnako Jamal Amen (MSc) ${ }^{1}$, Omer Ali Rafiq Barawi (MBCHB, FICMS ${ }^{2}$, Ahmed \\ Alkhuzai (FICMS $)^{3}$ and Shirwan Hamasalh Omer(MD,PhD) ${ }^{4}$ \\ Abstract
}

Background: Cerebral palsy $(\mathrm{CP})$ is a heterogenous permanent neurological disorder that is caused by a non-progressive damage to the developing brain. In this disorder, injury or malformation occurs in the growing central nervous system which eventually will affect the development of motor function and body posture before, during, or shortly after birth.

Objective: To estimate and highlight the status of demographic and clinical characteristics of cerebral palsy in children at Sulaymaniyah province which has significant walking disorders. Patients and Methods: In this study (118) ambulatory patients with cerebral palsy who attended the health care and consultation clinic at Children Rehabilitation Center (CRC) in Sulaymaniyah province. The primary data were studied according to: gender distribution, patient age, types of delivery, and age of presentation of the CP disorder. Additionally, the conditions at birth such as asphyxia, kernicterus, types of cerebral palsy, full-term, and preterm were studied. Finally, the Gross Motor Function Classification System (GMFCS) of cerebral palsied children was identified.

Results: Our data showed that females tend to be more affected by CP than males with a ratio of (65:53). The range of ages was between half a year and 12 years (mean of 7.5 years). The highest range appearance of cerebral palsy was between the ages of (12-24) months with a percentage of (58.47\%). A delayed milestone was the most common presenting among CP types (41.53\%). In comparison to the other $\mathrm{CP}$ types, the spastic type was the most common (59.32\%). The most prevalent subtype of CP was the spastic hemiplegia (40\%). 66.10\% of patients were born with vaginal delivery. The majority of the patients were born with asphyxia $(31.36 \%)$ followed by kernicterus direct antepartum. Sixty-seven $(56.78 \%)$ mothers were using medications during pregnancy. Forty-eight of parents were consanguine marriage. According to the GMFCS results, most of the CP patients were in the level III and level IV with $27.12 \%$, $25.42 \%$ respectively; the major motor disability in children with spastic hemiplegia varied from level I to III.

Conclusion: We deduced that it is difficult to estimate and clarify the exact cause and risk factors associated with the cerebral palsy disorder. However; we found spastic hemiplegia is the most common clinical pattern of $\mathrm{CP}$ due to its high prevalence of birth asphyxia. Using medicine during pregnancy will increase a chance of $\mathrm{CP}$ to occurs, for further investigation, the case-control study should be employed within the cohort study. 
Keywords: Ambulatory CP Child, Delayed milestones, Convulsion, Asphyxia, Outcomes, Sulaymaniyah province.

Corresponding Author: zmnako.amen@univsul.edu.iq

Received: $20^{\text {th }}$ January 2020

Accepted: $12^{\text {th }}$ March 2020

DOI:https://doi.org/10.26505/DJM.19015210120

${ }^{1,2,3,4}$ College of Medicine - Sulaymaniyah University- Sulaymaniyah - Iraq

\section{Introduction}

It is well-known that the term "Cerebral" refers to the brain and "Palsy" means a lack of control in muscles [1]. As described by Rosenbaum : "Cerebral palsy describes a group of permanent disorders of the development of movement and posture, causing activity limitations that are attributed to non-progressive disturbances that occurred in the developing fetal or infant brain. The motor disorders of cerebral palsy are often accompanied by disturbances of sensation, perception, cognition, communication, and behavior, by epilepsy, and by secondary musculoskeletal problems" [2]. These disorders are credited to non-progressive unsettling influences within the creating fetal brain, modification in fetal improvement, pathologic intrauterine forms, or considered as rashness complications [3].

Spasticity is the foremost common sort of motor disturbance; epilepsy, mental retardation, vision and hearing impairment are the most common associated problems [4]. CP is a static neurologic condition that occurs before the completion of cerebral development. Because brain development continues during the first two years of life, cerebral palsy can result from brain injury occurring during the prenatal, perinatal, or postnatal periods [5]. The most unfavorable brain accidents that put infants born preterm at high threat for $\mathrm{CP}$ are excessive intraventricular hemorrhage (IVH) and cystic periventricular leukomalacia (c-PVL) [6]. The analysis for neurodevelopmental outcomes of infants after a severe hemorrhage or c-PVL depends on the localization and quantity of the lesion [6]. Complications like low delivery weight, asphyxia at the start, untimely separation of the placenta, and ordinary fetal position had been associated with this disease. If a mother or infant suffers from any of these associated conditions, it does not mean it will result in $\mathrm{CP}$, rather it means higher prevalence of $\mathrm{CP}$ [7].

Congenital malformations, fetal boom limit, multiple gestations, untreated maternal hypothyroidism, perinatal stroke, and thrombophilia have been all identified as risk factors for CP [3]. Although the reasons for congenital cerebral palsy are not acknowledged within the majority of instances, there may be an evidence that elements present during the prenatal length play a distinguished function [8]. Twins also have a better frequency of malformations and $\mathrm{CP}$ than singletons [3]. In approximately 10 
to 20 percent of patients, cerebral palsy is received postnatally particularly because of brain harm from bacterial meningitis, viral encephalitis, hyperbilirubinemia, child abuse, road traffic accident or fall from height [5]. The CP prevalence occurs in $2.5 \%$ in step with thousand live births globally, and this abnormality varies with its involvement distribution like hemiplegia, diplegia, and adjustments with age and surgery [9].

Due to the lack of specific diagnostic criteria for $\mathrm{CP}$, variations in these specific incidence rates are evident. Some studies have been done to investigate all possible risk factors and report a general incidence rate for the $\mathrm{CP}$. Here, we estimated the risk factors and causes of cerebral palsy in ambulatory children in order to highlight the important criteria related to the $\mathrm{CP}$ syndrome.

\section{Patients and Methods}

This study has been conducted on patients who were admitted to the Children Rehabilitation Center (CRC) in Sulaymaniyah province from the first of June 2016 to the end of November 2019. For gathering the medical information on the $\mathrm{CP}$ patients, a questionnaire was filled with the assistance of parents and the birth enlistment record division. The study was formed concerning only those children with $\mathrm{CP}$ who were born in the province during that period. Clinical features and incidence ratio of 118 children (65 females: 53 males) with CP were diagnosed and studied. The age range of $\mathrm{CP}$ patients was between $(0.5-12)$ years. The consanguinity between partners and some fundamental criteria such as gravidity, parity, and abortion were taken into account.

The gender, age of the patients, types of delivery, status at birth especially birth asphyxia and kernicterus postnatally, types of cerebral palsies with the period's appearance of the disease, prematurity, and full-term born were all reviewed and studied. Furthermore, some associated medical abnormalities like mental retardation, microcephaly head, hearing complications with impaired vision, persistent chest infections problems, and epilepsy were investigated. The intellectual ability and associated medical impairments were collected from the medical record and data registrations.

The Gross Motor Function Classification System (GMFCS) was used for classifying the functional impairment and acuteness types of CP. The "GMFCS is a five-level pattern recognition system with level I describing the best gross motor abilities possible and Level $\mathrm{V}$ the worst. GMFCS levels I-II descriptions refer to walking without and with limitations, whereas GMFCS levels III-V descriptions refer to walking with a mobility device through to being transported in a wheelchair" [6]. For classification of the $\mathrm{CP}$ types, subtypes (topographic), limb distribution, and motor impairment; we utilized the Surveillance of Cerebral Palsy in Europe [6].

\section{Statistical analysis}

Mean and percentage results, figures, and tables were obtained using Excel and MATLAB package. 


\section{Results}

For clarity and simplicity purposes, we have summarized all estimated data in tables and as shown below.

Table (1): Types of cerebral palsies. The spastic type is the most common among all other types, while the Choreo-athetoid type is the least common one

\begin{tabular}{|c|c|c||}
\hline Type of CP & Number of patients & Percentage (\%) \\
\hline \hline Spastic & 70 & 59.32 \\
\hline \hline Ataxic & 19 & 16.10 \\
\hline \hline Hypotonic & 14 & 11.86 \\
\hline \hline Mixed & 8 & 6.78 \\
\hline \hline Chorio- athetoid & 7 & 5.93 \\
\hline \hline Total & 118 & 100 \\
\hline
\end{tabular}

Table (2): Topographical distribution of motor impairment of the $\mathrm{CP}$ patients. The hemiplegic $\mathrm{CP}$ is the most common and quadriplegic $\mathrm{CP}$ comes in the second- order then diplegic one

\begin{tabular}{|c||c||c||}
\hline Spastic CP & Number of patients & Percentage (\%) \\
\hline \hline Hemiplegic & 28 & 40.00 \\
\hline \hline Quadriplegia & 24 & 34.29 \\
\hline \hline Diplegic & 18 & 22.86 \\
\hline \hline Total & 70 & 100 \\
\hline
\end{tabular}

Table (3): Results of the CP involvement distribution according to their ages. The most period for the appearance of the CP symptoms is between 12-24 months due to the development of the brain continually

\begin{tabular}{|c||c|c||}
\hline Range of age in month & Number of patients & Percentage (\%) \\
\hline \hline $6-11$ & 27 & 22.88 \\
\hline \hline $12-24$ & 69 & 58.47 \\
\hline \hline Greater than 24 month & 22 & 18.46 \\
\hline \hline Total & 118 & 100 \\
\hline
\end{tabular}

Table (4): Type of delivery of the CP patients. Though most of the CP patients were born with normal delivery, but they ended with $\mathrm{CP}$ symptoms that might be a result of some other conditions

\begin{tabular}{|c||c||c||}
\hline Mode of birth & Number of patients & Percentage $(\%)$ \\
\hline \hline Normal delivery & 78 & 66.10 \\
\hline \hline Cesarean section & 34 & 28.81 \\
\hline \hline Forceps delivery & 6 & 5.08 \\
\hline \hline Total & 118 & 100 \\
\hline
\end{tabular}


Table (5): Disparities between male and female, full-term and preterm born with mothers using medicine and non-medication during the pregnancy. The affected $\mathrm{CP}$ females were slightly higher than in males. The full term born is about twice in comparison with preterm born. Number of mothers who were using the medicine during the pregnancy is higher than those who did not use it

\begin{tabular}{|c||c|c|}
\hline & Number of patients & Percentage (\%) \\
\hline \hline Female & 65 & 55.08 \\
\hline \hline Male & 53 & 44.92 \\
\hline \hline Full term & 78 & 66 \\
\hline \hline $\begin{array}{c}\text { Using medicine during } \\
\text { pregnancy }\end{array}$ & 40 & 34 \\
\hline \hline $\begin{array}{c}\text { Using not medicine } \\
\text { during pregnancy }\end{array}$ & 67 & 56.78 \\
\hline
\end{tabular}

Table (6): Mother's complications during pregnancy and their obedience to antenatal care. The majority of mothers do not have any diseases during pregnancy. Twenty-one mothers had diabetic and thirteen mothers had preeclampsia toxemia

\begin{tabular}{|c|c|c|}
\hline & Number of patients & Percentage (\%) \\
\hline \hline $\begin{array}{c}\text { Attend antenatal care } \\
\text { regularly }\end{array}$ & 84 & 71.19 \\
\hline \hline Diabetic mother & 21 & 17.80 \\
\hline \hline Preeclampsia toxemia & 13 & 11.02 \\
\hline \hline Total & 118 & 100 \\
\hline
\end{tabular}

Table (7): Clinical features and relevant abnormalities of the CP patients. The delayed milestone is the highest rate comparing to some other associated abnormalities. The second major abnormality is the convulsion

\begin{tabular}{|c|c|c|}
\hline Relevant abnormalities & Number of patients & Percentage (\%) \\
\hline \hline Delayed milestones & 49 & 41.53 \\
\hline \hline Convulsion & 23 & 19.49 \\
\hline $\begin{array}{c}\text { Difficulty in } \\
\text { swallowing }\end{array}$ & 12 & 10.17 \\
\hline $\begin{array}{c}\text { Hearing and visions } \\
\text { problems }\end{array}$ & 10 & 8.47 \\
\hline $\begin{array}{c}\text { Disable to move one } \\
\text { hand and hand } \\
\text { preference }\end{array}$ & 9 & 7.36 \\
\hline \hline $\begin{array}{c}\text { Recurrent chest } \\
\text { infection }\end{array}$ & 8 & 6.78 \\
\hline \hline Epilepsy & 7 & 5.93 \\
\hline \hline Total & 108 & 100 \\
\hline
\end{tabular}


Table (8): Number of children with their percentage they had with the condition time's birth. Birth asphyxia, kernicterus, and low birth weight were the most conditions at birth respectively. About $21.19 \%$ percent of the CP patients had no condition at birth, but they ended with this symptom, those CP patients may affect prenatal or perinatal periods

\begin{tabular}{||c||c|c|}
\hline Condition at birth & Number of patients & Percentage (\%) \\
\hline \hline Birth asphyxia & 37 & 31.36 \\
\hline \hline No condition at birth & 25 & 21.19 \\
\hline \hline Kernicterus & 21 & 17.80 \\
\hline \hline Low birth weights & 19 & 16.10 \\
\hline \hline Microcephaly & 12 & 10.17 \\
\hline \hline Twins or Triples & 4 & 3.39 \\
\hline \hline Total & 118 & 100 \\
\hline
\end{tabular}

Table (9): GMFCS results of the CP children. According to the functional classification, most of the CP patients were falling in levels III, V and IV

\begin{tabular}{|c||c|c|}
\hline \multicolumn{1}{|c|}{ GMFCS } & Number of patients & Percentage (\%) \\
\hline \hline Level I & 6 & 5.08 \\
\hline \hline Level II & 17 & 14.41 \\
\hline \hline Level III & 32 & 27.12 \\
\hline \hline Level IV & 30 & 25.42 \\
\hline \hline Level V & 33 & 27.97 \\
\hline \hline Total & 118 & 100 \\
\hline
\end{tabular}

\section{Discussion}

Spastic CP was the predominant type in this study. Our data showed that $60 \%$ of all patients had this type which is the same percentage reported by some previous studies $[10,11]$. It followed by ataxic type (16.10\%). The most prevalent subtype of the spastic cerebral palsy among the children was the spastic hemiplegia ( $40 \%$ of seventy patients). While our data showed that the most range of age presentations of the $\mathrm{CP}$ is (12-24) month $(58.47 \%)$, other studies showed that the highest rate of the age distribution of $\mathrm{CP}$ has happened in patients with age (7-12) month $[10,11]$. The clinical findings in some affected children appear to evolve and the affected children may exhibit some different distributions of involvement at different ages [10].

In our study, the majority of the $\mathrm{CP}$ patients was delivered by a normal vaginal delivery followed by a cesarean section and forceps delivery which agrees with the results documented in some previous studies $[10,11]$. However; the cesarean section is well simplified for the baby from difficult labor especially for the primigravida in some women and cord contortion around the neck or hands which helps minimizing the chance for the CP occurrence. Those children suffer from brain-damage in the prenatal period or could occur intrapartum or antepartum [12]. While our results showed that there is a slight 
predominance of females as shown in Table (5), other studies showed that males were the predominant $[10,11]$. This could be due to that some of the patients were living outside the city (rural areas) who may not be registered by CRC- Sulaymaniyah or by chance in that period the born females were more than males.

The full terms born (66\%) were higher than those born with pre-terms $(34 \%)$, this is the same as in other previous studies $[10,11]$. From all full-term born, twenty percentages of the patients had asphyxia at birth and kernicterus postnatal; this might be a reason for accruing the $\mathrm{CP}$ in those children. A previous study [3] confirmed that the risk factor of $\mathrm{CP}$ is gestational age subordinate, and it is much more predominant among preterm neonates, particularly those who were greatly untimely. The mothers were using the medicine during pregnancy higher than those who were not using it showed in Table (5). Most of the mothers were using the tonics, multi-vitamin and sometimes analgesic like Paracetamol. Few of the mothers were using Thyroxine medication and antibiotics. It seems that using the medicine during pregnancy increases the chance of CP occurrence. A study has found a link between a certain class of antibiotics and a higher incidence of cerebral palsy and epilepsy $[13,14]$. While the findings have led some scientists to caution against the use of certain antibiotics during pregnancy, leaving infections untreated continues to be considered a higher risk for unborn children [14].
$71 \%$ of mothers have attended the consultation clinic but still had born with $\mathrm{CP}$ rather than normal. The reasons for this could this: though there is advanced equipment available for the early diagnoses of the $\mathrm{CP}$ but those clinical consultations do not have adequate facilities for the fetal management or those $\mathrm{CP}$ patients may be affected during the birth or postnatally. Twenty-one $(17.80 \%)$ of mothers were diabetic during pregnancy, those $\mathrm{CP}$ patients could be related to the congenital malformation or any relevant factor associated with the development of CP. There is a previous study that investigated the correlation between different pre-birth issues and $\mathrm{CP}$ pathogenesis [4]. Regarding maternal disorders during pregnancy, our study showed that mothers of $13(11 \%)$ patients with CP had a history of preeclampsia which agrees with the study that has done in [15]. "Preeclampsia is associated with an increased risk of cerebral palsy in term infants, but this association does not seem to exist in preterm infants" [16]. "Alternatively, the presence of preeclampsia may result in elective preterm delivery, avoiding the inflammatory responses of spontaneous preterm labor with all their associated problems" [16].

The most frequently observed abnormality of the $\mathrm{CP}$ patients was a delayed milestone and found in forty-nine (41.53\%) patients, this result agrees with studies presented in $[10,11]$. It is well suggested that the diagnosis of the $\mathrm{CP}$ is first predicted by parents. They observe some of the child motors developments especially after six 
months when the child begins with crawling, rolling and sitting. Particularly among infants born prematurely, neurological abnormalities, observed in the early months of life, may not be associated with motor impairment and may resolve during the first one or two years of life [17]. In our study, perinatal asphyxia was the main perinatal etiology; thirty-seven $(31.36 \%)$ patients had asphyxia during delivery. Studies have shown that birth with hypoxia has a high prevalence of subtype quadriplegia CP [18]. Other study documented that perinatal asphyxia considered to be less than 10-20\% [4].

Twenty-five (21.19\%) patients born without any condition but they had well cerebral palsy. A study estimated that about $80 \%$ of CP cases are of unknown etiology [19]. Among all the patients there were 3 patients who had acquired cerebral palsy, two of them were victims of accidental cars and the other fell down during the delivery. Twenty-one $(17.80 \%)$ patients had jaundice directly after the delivery. When extreme jaundice goes untreated for a long time, it can cause condition of kernicterus, afterward accurses the athetoid cerebral paralysis and hearing misfortune. Kernicterus also causes issues with vision and teeth. It can cause mental incapacities as well [20]. Nineteen (16.10\%) patients were born with low birth weights. Prematurity has been recognized as the main risk factor for CP [4]. Severe intraventricular hemorrhage and cystic periventricular leukomalacia put the infants born preterm and regarded as the highest relative risk for the $\mathrm{CP}$ [7,21]. Twelve $(10.17 \%)$ patients had microcephaly. Intrinsic microcephaly is the foremost common birth imperfection in CP as was reported in [3].

Four $(3.39 \%)$ patients were twins, no cases were both twin siblings affected. Twin and triplet pregnancies are more common in Invitro Fertilization (IVF) programs and there is a few concerns that certain methods to progress IVF results may incline the newborn child to $\mathrm{CP}$ and other formative disorders [22]. The mutations of twins have the next recurrence $\mathrm{CP}$ than singletons; moreover the in utero passing of one twin, indeed on the off chance that it happens early in incubation, takes off the surviving twin at an extraordinarily expanded chance for CP [3]. Forty-eight $(40.68 \%)$ parents were consanguine marriages, which may explain a genetic affection. However, there is no evidence that the antecedence will be a risk factor for CP [23], but it is advisable to decrease consanguineous marriage [9,24].

Figure (1) shows the types of $\mathrm{CP}$ according to their GMFCS levels. The mild gross motor disability (levels I and II) existed in 23 (19.50\%) children; hemiplegia 9 patients, diplegia 8 patients, and quadriplegia were 6 patients. Thirty-two $(27.12 \%)$ patients were fallen in level III which was consisted of; 19 hemiplegias, 10 diplegia, and 3 chorioathitoid with hypotonic. $53.4 \%$ of children with mixed type of $\mathrm{CP}$, ataxic and chorioathitoid, hypotonic type and quadriplegia were fallen in the levels IV and V. From level I to level III, the most major motor disability with spastic hemiplegia was 
observed, while the severest CP group varied hypotonic and quadriplegia in a subtype of from levels IV to $\mathrm{V}$ which were the ataxic, spastic cerebral palsy.

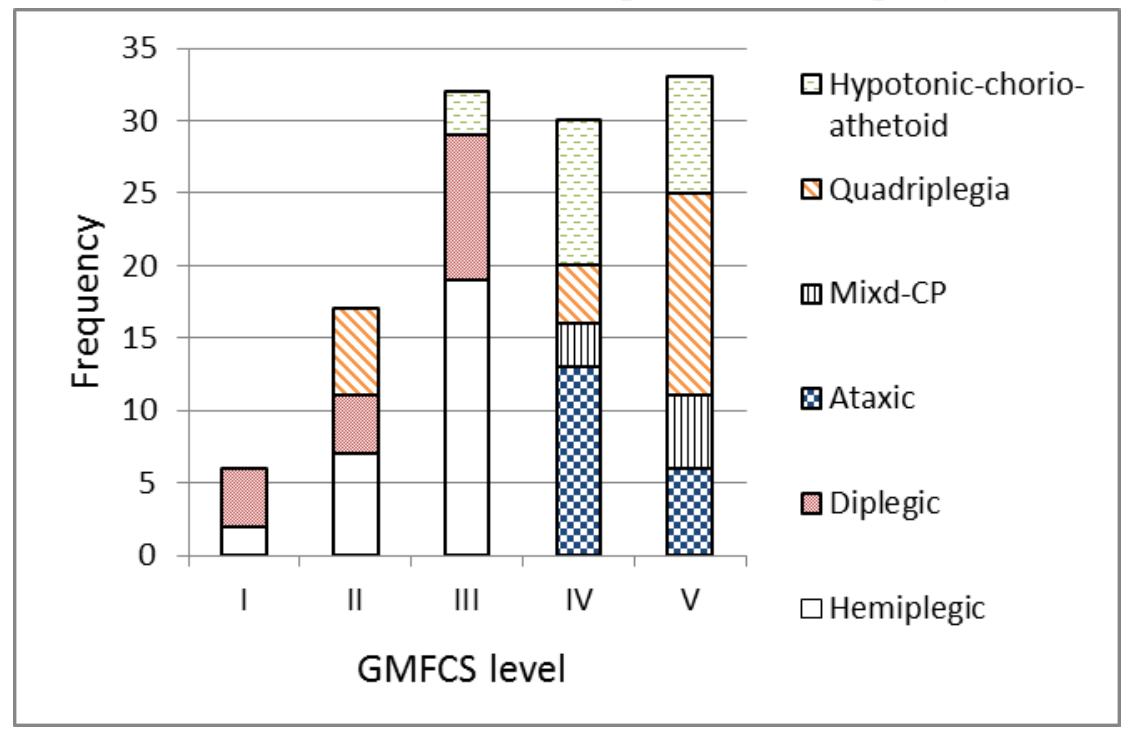

Figure (1): Types of cerebral palsy according to the GMFCS

\section{Conclusions}

The main conclusion of our study is that it is difficult to get an estimation and clarification of the exact cause and risk factors that could be associated with the cerebral palsy disorder. However; we found that spastic hemiplegia is the most common clinical pattern of $\mathrm{CP}$ due to its high prevalence of birth asphyxia. Using medicine during pregnancy will increase a chance of $\mathrm{CP}$ to occur. As a future goal, a further investigation will employ the case-control study within each cohort.

\section{Recommendations}

1-To reduce the rate of cerebral palsy, it's better to improve neonatal care units and support them with more powerful diagnostic equipment especially in the developing countries.
2-Improvements a bed for pregnant women to avoid falling down the baby during the delivery time so that the gestation not falling down on the ground.

3-We also recommend using the continuous positive airway pressure (CPAP) for each newborn to reduce the chance of hypoxic ischemic encephalopathy (HIE) and preventing the $\mathrm{CP}$.

4-Establish special centers to care for those children especially those who need traditional physiotherapy, hydrotherapy, and occupational therapist. Besides this, there should be centers for those children to care for them until their parents come back from their jobs.

\section{References}

[1]Rana M, Upadhyay J, Rana A, Durgapal S, Jantwal A. A Systematic Review on Etiology, Epidemiology, and Treatment of 
Cerebral Palsy. International Journal Of Nutrition, Pharmacology, Neurological Diseases. 2017 Oct 1; 7(4):76.

[2]Rosenbaum P, Paneth N, Leviton A, Goldstein M, Bax M, Damiano D, Dan B, Jacobsson B. A report: the definition and classification of cerebral palsy April 2006. Dev Med Child Neurol Suppl. 2007 Feb 1; 109(suppl 109):8-14.

[3]Stavsky M, Mor O, Mastrolia SA, Greenbaum S, Than NG, Erez O. Cerebral palsy - trends in epidemiology and recent development in prenatal mechanisms of disease, treatment, and prevention. Frontiers in pediatrics. 2017 Feb 13; 5:21.

[4]Drougia A, Giapros V, Krallis N, Theocharis P, Nikaki A, Tzoufi M, Andronikou S. Incidence and risk factors for cerebral palsy in infants with perinatal problems: a 15-year review. Early human development. 2007 Aug 1; 83(8):541-7.

[5]Krigger KW. Cerebral palsy: an overview. American family physician. 2006 Jan 1; 73(1):91-100.

[6]Van Haastert IC, Groenendaal F, Uiterwaal CS, Termote JU, van der HeideJalving M, Eijsermans MJ, Gorter JW, Helders PJ, Jongmans MJ, de Vries LS. Decreasing incidence and severity of cerebral palsy in prematurely born children. The Journal of pediatrics. 2011 Jul 1; 159(1):8691.

[7] Torfs CP, van den Berg BJ, Oechsli FW, Cummins S. Prenatal and perinatal factors in the etiology of cerebral palsy. The Journal of pediatrics. 1990 Apr 1; 116(4):615-9.
[8]Croen LA, Grether JK, Curry CJ, Nelson KB. Congenital abnormalities among children with cerebral palsy: more evidence for prenatal antecedents. The Journal of pediatrics. 2001 Jun 1;138(6):804-10.

[9]Nelson KB, M.D. Can we prevent cerebral palsy? The New England journal of medicine. 2003; 349(18):1765-1769.

[10]Hassan KH. Cerebral palsy among Kurdish children in the city of Dohuk: a caseseries study. Jordan Medical Journal. 2009; 43(3):205-11.

[11]Al-Azzawi DS. Demographic and clinical characteristic of Cerebral Palsy Among Children in Diyala Province-Iraq. Diyala Journal of Medicine. 2012; 2(1):72-8. [12]Hagberg H, Edwards AD, Groenendaal F. Perinatal brain damage: the term infant. Neurobiology of disease. 2016 Aug 1; 92:102-12.

[13] JE, Pedersen LH, Streja E, Bech BH, Yeargin-Allsopp M, Van Naarden Braun K, Schendel DE, Christensen D, Uldall P, Olsen J. Maternal infections during pregnancy and cerebral palsy: a population-based cohort study. Paediatric and perinatal epidemiology. 2013 Nov; 27(6):542-52.

[14]Whitney Taylor. Epilepsy \& Cerebral Palsy Linked to Antibiotics During Pregnancy

APRIL 1, 2015: BIRTH INJURY. [15]AL-Naddawi MN, Saadi NW, Abid AR. Risk Factors \& Clinical Patterns of Cerebral Palsy in Children Welfare Teaching Hospital in Baghdad. Iraqi Academic Scientific Journal. 2011; 10(3):284-92. 
[16]Kurt EE. Definition, Epidemiology, and Etiological Factors of Cerebral Palsy. In Cerebral Palsy-Current Steps 2016 Sep 21. IntechOpen.

[17]O'Shea TM. Diagnosis, treatment, and prevention of cerebral palsy in nearterm/term infants. Clinical obstetrics and gynecology. 2008 Dec; 51(4):816.

[18]Al-Omeri W. Cerebral palsy an almost cleared old obstetrician's stigma. The abstract book of the scientific committee of Iraqi medical association, 2002.

[19]Odding E, Roebroeck ME, Stam HJ. The epidemiology of cerebral palsy: incidence, impairments and risk factors. Disability and rehabilitation. 2006 Jan 1; 28(4):183-91.

[20]Arthur J, Ezell S, Schultz M, Stevens P. How Innovators Are Solving Global Health Challenges. Centers for Disease Control and Presentation; Saving lives Protection people; https://www.cdc.gov/ncbddd/jaundice/facts.h $\underline{\mathrm{tml}}$.

[21]Volpe JJ. Brain injury in premature infants: a complex amalgam of destructive and developmental disturbances. The Lancet Neurology. 2009 Jan 1;8(1):110-24.

[22]Eunson P. Aetiology and epidemiology of cerebral palsy. Paediatrics and Child Health. 2012 Sep 1; 22(9):361-6.

[23]Stanley FJ, Blair E, Alberman E. Cerebral palsies: epidemiology and causal pathways. Cambridge University Press; 2000 Jan 18.

[24] Blair E, Watson L. Epidemiology of cerebral palsy. InSeminars in Fetal and Neonatal Medicine 2006 Apr 1 (Vol. 11, No. 2, pp.117-125). WB Saunders. 